\title{
Pediatric versus adult MS: similar or different?
}

\author{
Angelo Ghezzi ${ }^{{ }^{*}}$, Damiano Baroncini ${ }^{1}$, Mauro Zaffaroni ${ }^{1}$ and Giancarlo Comi ${ }^{2}$
}

\begin{abstract}
In this review the most important aspects of pediatric multiple sclerosis are presented and compared with the adult form. Some findings appear peculiar of pediatric MS:

a. Clinical manifestations are similar in adolescents and adults with MS, however in very young subjects MS frequency at onset is similar in males and females, with a higher frequency of brainstem/cerebellar involvement and acute polysymptomatic/ADEM like onset;

b. The course is relapsing-remitting in the large majority of patients, with a high relapse rate;

c. Mild or severe disability is reached after a longer interval, but at a lower age compared to adult MS;

$\mathrm{d}$. The frequency of cognitive dysfunction is relatively high, with a quick deterioration but also the capability to partially recover with time;

e. MRI is fundamental for diagnosis and prognosis: the pattern of MRI has some peculiar aspects in pediatric MS patients: i) the classic diagnostic criteria cannot be fulfilled, ii) lesion load is more relevant, iii) lesions are less destructive, have a more pronounced inflammatory pattern and have enhanced capability to recover with time;

f. Diagnostic criteria of adults can be applied to patients with less than 18 years, but with limitations for subjects with less than 12 years and ADEM-like onset;

g. The approach in differential diagnosis is particular complex and many disorders with clinical manifestations in the pediatric age must be considered: in this context it is important to pay attention to clinical, MRI and CSF red flags. Anti-MOG abs syndrome has been recently identified and should be carefully considered in patients with Acquired Demyelinating Syndrome;

h. CSF oligoclonal bands are less frequent in pediatric MS patients, their presence in patients with Acquired Demyelinating Syndrome is strongly correlated to the risk of MS;

i. The interplay between genetic and environmental factors determine the risk of developing MS;

j. MS has a more pronounced inflammatory pattern (as suggested by the high relapse rate and the most relevant inflammatory pattern at brain MRI);

k. The treatment is based on the approach used for adults: as MS has a strong impact on patients and their family the model of care should involve a team with specialized neurologists, pediatricians and neuro-pediatricians, nurses, psychologists, social workers and specialists of rehabilitative medicine.
\end{abstract}

Keywords: Pediatric multiple sclerosis, Acquired Demyelinating Syndrome, Cognitive dysfunction, Diagnosis, Differential diagnosis, MRI, CSF, Genetic factors, Environmental factors, Therapy

\footnotetext{
* Correspondence: angelo.ghezzi@asst-valleolona.it

${ }^{1}$ Centro Studi Sclerosi Multipla, ASST Valleolona, Via Pastori 4, Gallarate 21013, Italy

Full list of author information is available at the end of the article
} 


\section{Background}

Multiple sclerosis (MS) typically starts between 20-40 years of age, but it is increasingly recognized in young subjects, before 18 years of age: according to literature data about $3-10 \%$ of all MS cases have their first manifestations in childhood or adolescence [1, 2]. According to the definition of the International Pediatric MS Study Group, the pediatric onset applies to patients with less than 18 years of age, having in mind that children (arbitrarily defined as aged less than 10-12 years) can present some different clinical and laboratory features, requiring a particular care when applying diagnostic criteria and planning treatment interventions [1-3].

The incidence of cases with a first acute episode of presumed inflammatory cause (otherwise called Acquired Demyelinating Syndrome -ADS-) per year varies from 0.6 to 1.9 per 100,000 , in relation to different geographic areas (Holland [4], Canada [5], USA [6]) and probably to the methods of cases ascertainment. Some recent studies $[7,8]$ have reported a higher incidence, up to 2.85/ 100,000 for pediatric-MS (ped-MS) cases in Sardinia (Italy) [7].

Many factors have contributed to increase the interest towards pediatric MS, mainly: the closer collaborations among specialists (neurologists, neuropediatricians, pediatricians), the definition of shared diagnostic criteria, the possibility to use effective medications, and, from a scientific point of view, the possibility to better explore risk factors as pediatric patients are closer to the real onset of the disease, compared to adults.

In addition to numerous studies carried out in NorthAmerica and Europe, recent studies have been published on pediatric cohorts of selected populations (Hispanic North-Americans) [9] or from other countries such as Turkey, Kuwait, Iran, Brazil, Marroch, Korea and Japan [10-17], indicating an increased interest in this area of clinical research. Many papers have been recently published giving a better definition of incidence, clinical aspects, pathophysiology, immunology, neuroimaging and treatment: a summary of these studies is provided by a recent publication of the International Pediatric MS Study Group [18].

The objective of this presentation is to summarize the most important advances on ped-MS research and to offer a guidance among the most meaningful contributions, with a focus on the basic question, whether ped-MS form is the same disease of the adult form or not.

\section{Clinical aspects: how similar to adult MS?}

Many reviews are available describing clinical features of ped-MS [1, 2, 4, 19, 20]; the objective here is to highlight the peculiar and distinctive aspects of this form compared to the adult one.
As in adult MS, females are more frequently affected than males with a ratio of about $3: 1$, but in subjects less than $10-12$ years $\mathrm{f} / \mathrm{m}$ ratio is about $1: 1[19,21-25]$, suggesting that sex hormones can have a role in facilitating MS onset during puberty [26-28]. Hormones can also facilitate the development of relapses, as they are more frequent during the peri-menarche compared to post-menarche period [28]. Experimental studies have confirmed the role of sex hormones in the development of EAE [26].

Symptoms at presentation are in general similar to those observed in adults $[1,19,20]$ but two findings are described as typical of ped-MS:

- the ADEM-like onset (acute polysymptomatic onset with encephalopathy) especially in children [1, 29, 30];

- the frequent initial presentation with symptoms indicating cerebellar or brainstem involvement $[10,17,19,21]$.

In addition, very young patients, in general with age < 12 , are likely to present a polysymptomatic onset, a high number of relapses, a more severe clinical involvement, and a worse prognosis $[10,17,19,21]$.

The course is progressive in about $10 \%$ of patients with adult-MS but this evolution is exceptional in ped-MS [1]. Typically ped-MS patients present a relapsing-remitting (RR) course with an high relapse rate, at least in the initial phase of disease, about twice higher than that of the adult form [31, 32], although this finding has not been confirmed in all studies [10, 11, 21]. Relapse rate as well accumulation of disability and early shift to progression have been recognized as factors correlated to a negative prognosis $[1,19,33,34]$.

In spite of the high relapse rate, the time to reach mild or severe disability is longer in ped-MS than in adultMS, with a delay of about 10 year; as a counterpart the age when these levels of disability are reached is about 10 years lower [10, 19, 21, 33-35], raising the question whether ped-MS is more benign or not with respect to the adult form; it could be considered more benign if the time to reach disability is considered, but more severe if the actual age is taken into account. This issue will also be discussed further on Conclusions.

In the late years there has been an increasing interest in exploring the presence and the pattern of cognitive dysfunction (CD) in ped-MS. Some reviews have recently summarized the most outstanding aspects of this issue [36-38], which are summarized below. Briefly:

- CD is found in about 30-50\% of cases, some of them with a low IQ [38-40], and also in $18 \%$ of subjects at MS onset [40]; 
- Patients with a younger age at MS onset [39, 41, 42], a longer disease duration $[41,42]$ and a higher disability $[40,42]$ are more at risk of CD;

- the most frequently affected functions are attention, language (receptive, verbal fluency and naming); visual-spatial and motor functions, spatial memory, executive functions and abstract reasoning.

- Language impairment [39] and impairment in information-processing speed are more pronounced in pediatric than in adult MS [43];

- fatigue, affective disorders (anxiety, depression), behavioural problems (somatization, attention problems) are commonly observed [38, 39, 44, 45];

- psychological and behavioural problems have a negative impact on executive function [45], and are strongly associated with CD [46];

- CD has a negative effect on quality of life and is related to limitations in social, academic and recreational activities [38, 39];

- social cognition (the capability of inferring another's mental state, knowledges, beliefs and emotions) is also affected, compromising social relationships and contributing to mental decline [47];

- stable in the short term [48], CD increases in frequency and severity with time [49-51]. A study has demonstrated a partial recovery after a phase of deterioration, anyway remaining more severe compared to baseline [49], suggesting a better capability of the brain of children to compensate brain damage, compared to adults;

- CD is correlated with brain MRI structural (lesion load, location of lesions) and functional alterations, detectable with non-conventional techniques [52-55];

- The cognitive background (the so called "cognitive reserve") has a significant role in protecting against cognitive decline [56];

The latest findings (increased severity of $\mathrm{CD}$ with time, effects on social functioning) indicate how severe is the effect of MS on subjects $[57,58]$. Nevertheless, in spite of this severity, the brain of pediatric patients exibits an high capability to compensate the damage: this finding is supported by the possibility to partially reduce the extent of $\mathrm{CD}$ in the long-term, and by studies with functional and nonconventional MRI demonstrating an higher plasticity of the brain. It has been demonstrated that the activation of brain areas after a simple movement of the hand, that is progressively more widespread with progression of MS, is more restricted in pediatric compared to adult MS [59], indicating a relatively preserved functional organization of the brain; moreover the pattern of connectivity among brain areas is more efficient in children, compared to adults (see also Differential diagnosis: can clinical manifestations and ancillary investigations make the difference? section).
The issue of cognitive reserve, together with the positive effect of physical activity on brain plasticity $[60,61]$ (see MRI: a true distinctive pattern in ped-MS? section), underlines the concept of an higher brain plasticity in pedMS, indicating that the enrichment and reinforcement of brain activity help the brain to better compensate the damage caused by MS [62].

In clinical practice it is advisable to explore the cognitive function in patients with ped-MS: short batteries have been proposed [63, 64], the Symbol Digit Modality Test has the advantage to be effective and easy to use [63].

\section{Diagnosis: are diagnostic criteria of MS applicable to the pediatric form?}

The pediatric form of MS has been included in the last revision of the McDonald diagnostic criteria of MS [65] on the consideration that most patients presenting a clinically isolated syndrome (CIS) before 18 years of age have the same pattern of adult-MS ( $>2$ lesions in 2 of the 4 specific CNS locations). However $15-20 \%$ of pediatric patients, mostly aged $<11$ years, can present with the so called acute disseminated encephalomyelitis (ADEM) pattern, suggesting caution in applying adult diagnostic criteria in these subjects, who are required to present 2 or more subsequent non-ADEM like attacks, or 1 non-ADEM like attack plus accrual of clinically silent lesions on MRI during the follow up, for the final diagnosis of MS.

The International Pediatric MS Study Group [3] has incorporated the revised McDonald criteria in the current classification of pediatric demyelinating disorders, that includes: patients with ADEM and its multiphasic form, clinically isolated syndrome (CIS), ped-MS, neuromyelitis optica (NMO). The Krupp's new diagnostic criteria are summarized in Table 1 [29]. Diagnosis of NMO has been recently revised according to new criteria [30].

The revised McDonald's criteria have been validated in cohorts of patients with less than 18 years, confirming their high sensitivity and specificity, meanwhile confirming the limitations when applied in patients with less than 11 years [66, 67].

It is worthy to remind that the pattern of MRI lesions typical of the adult form cannot always be found in children and adolescents with suspected (and sometimes confirmed) MS, a finding that has led to investigate whether a more specific pattern of lesions can be recognised in patients with suspected MS (Table 2). At present none of these proposals has been validated.

Spinal cord MRI can also provide further evidence of dissemination in time and space, although this aspect has not been systematically evaluated in young patients [68].

Brain MRI helps define the risk of developing MS after a first demyelinating episode: in a cohort of patients with ADS Verhey's criteria (simultaneous presence of one or more T2 periventricular lesions and one or more T1 
Table 1 Diagnostic criteria for Acquired Demyelinating Syndromes $[2,3]$

\begin{tabular}{|c|c|}
\hline $\mathrm{CIS}$ & $\begin{array}{l}\text { A first monofocal or multifocal CNS demyelinating } \\
\text { event; encephalopathy is absent, unless due to } \\
\text { fever }\end{array}$ \\
\hline Monophasic ADEM & $\begin{array}{l}\text { - A first polyfocal clinical CNS event with } \\
\text { presumed inflammatory cause } \\
\text { - Encephalopathy that cannot be explained by } \\
\text { fever is present } \\
\text { - MRI typically shows diffuse, poorly demarcated, } \\
\text { large, }>1-2 \mathrm{~cm} \text { lesions involving predominantly } \\
\text { the cerebral white matter; TI hypointense } \\
\text { white matter lesions are rare; Deep grey mat- } \\
\text { ter lesions (e.g. thalamus or basal ganglia) can } \\
\text { be present } \\
\text { - No new symptoms, signs or MRI findings after } \\
3 \text { months of the incident ADEM }\end{array}$ \\
\hline Multiphasic ADEM & $\begin{array}{l}\text { - New event of ADEM } 3 \text { months or more after } \\
\text { the initial event that can be associated with } \\
\text { new or re-emergence of prior clinical and MRI } \\
\text { findings. Timing in relation to steriods is no } \\
\text { longer pertinent. }\end{array}$ \\
\hline MS & $\begin{array}{l}\text { Any of the following: } \\
\text { - Two or more nonencephalopathic CNS clinical } \\
\text { events separated by more than } 30 \text { days, } \\
\text { involving more than one area of the CNS } \\
\text { - Single clinical event and MRI features rely on } \\
2010 \text { Revised McDonald criteriab for DIS and } \\
\text { DIT [4] (but criteria relative for DIT for a single } \\
\text { attack and single MRI only apply to children } \\
\geq 12 \text { years and only apply to cases without an } \\
\text { ADEM onset) } \\
\text { - ADEM followed } 3 \text { months later by a } \\
\text { nonencephalopathic clinical event with new } \\
\text { lesions on brain MRI consistent with MS }\end{array}$ \\
\hline NMO & $\begin{array}{l}\text { All are required: } \\
\text { - Optic neuritis } \\
\text { - Acute myelitis } \\
\text { - At least two of three supportive criteria: } \\
\text { - Contiguous spinal cord MRI lesion } \geq 3 \\
\text { vertebral segments } \\
\text { - Brain MRI not meeting diagnostic criteria } \\
\text { for MS } \\
\text { - Anti-aquaporin-4 lgG seropositive status }\end{array}$ \\
\hline
\end{tabular}

Table 2 Different MRI criteria for diagnosis of MS in pediatric patients

\begin{tabular}{lll}
\hline KIDMUS criteria & Callen's criteria & Verhey's criteria \\
\hline 1 of 2: & Diagnosis: 2 of 3 & 2 of 2: \\
- Lesions perpendicular to & $-\geq 2$ T2 weighted & -1 periventricular \\
long axis of the corpus & lesions & lesions \\
callosum & -2 periventricular & -1 hypointense \\
- Sole presence of well & lesions & lesions on T1 \\
defined lesions & $-\geq 1$ Brain stem & images \\
& lesion & \\
& MS vs ASEM, 2 of 3: \\
& - Absence of a diffuse \\
& bilateral lesion & \\
& pattern & \\
& - Presence of black \\
& holes & \\
& $-\geq 2$ periventricular \\
& lesions \\
\hline
\end{tabular}

hypointense lesions) were associated with an increased likelihood of MS diagnosis, with an high sensitivity and specificity; conversely the presence of contrast enhancement, cerebral white matter, intracallosal and brainstem lesions was not associated with an increased risk of MS [69]. The predictive role of Verhey's criteria has been validated in a large cohort of children with ADS [70]. Anyway, meeting or not the $2010 \mathrm{McD}$ onald criteria at onset does not correlate with subsequent clinical course [71].

CSF examination, to detect intrathecal IgG synthesis, is not formally included among diagnostic criteria, nevertheless it can give an additional considerable contribution for diagnosis in patients at their first clinical episode, in addition to MRI [29, 72, 73].

\section{Differential diagnosis: can clinical manifestations and ancillary investigations make the difference?}

The differential diagnosis is particularly complex in children and adolescents with suspected MS as many diseases with onset in the pediatric age must be considered. As for adult form the criterion of "no better explanation" is required for the final diagnosis of MS.

Many conditions can mimic MS clinically, such as systemic lupus erythematosus (SLE), Bechet disease, neurosarcoidosis, angiitis of the CNS, tumors, infections, neurometabolic, hereditary disorders and many others: a complete list is reported and discussed in the work of Rostasy et al. [74].

Atypical manifestations or symptoms such as seizures, headache, psychosis, cranial neuropathy, persistent or recurrent visual loss, retinopathy, peripheral neuropathy, progressive or recurrent encephalopathy, spastic paraplegia should induce to consider diagnostic alternatives as summarized in Table 3 [75].

The course of ped-MS is typically relapsing-remitting, the progressive evolution being exceptional. So far, an atypical presentation with an hyperacute, or subacute or progressive onset should advice to explore alternative diagnoses [1] (Table 4), although the final diagnosis of MS cannot be excluded if supported by appropriate laboratory findings.

In clinical practice ADEM is a frequent diagnostic problem as it can be difficult to differentiate from MS, and possibly being the first presentation of MS in some patients, especially the youngest. The demographic, clinical and laboratory findings summarized in Table 5 (from Krupp et al. modified) can help to differentiate the two disorders, having in mind that patients ADEM must be carefully followed for the possible risk of a subsequent MS.

Serum autoantibodies to myelin peptides could be helpful to distinguish ADEM from relapsing-remitting MS. In a study [76] ADEM was associated to IgG autoantibodies targeting epitopes derived from myelin basic 
Table 3 Clinical red flags for alternative diagnosis [74, 85]

\begin{tabular}{|c|c|}
\hline Red flags & Diagnosis to consider \\
\hline Seizures & $\begin{array}{l}\text { - Vasculitis } \\
\text { - tumor } \\
\text { - infection } \\
\text { - NMDA-receptor encephalitis }\end{array}$ \\
\hline Headache & $\begin{array}{l}\text { - Vasculitis } \\
\text { - Susac syndrome (visual/hearing loss) } \\
\text { - infection } \\
\text { - venous thrombosis } \\
\text { - cerebral edema } \\
\text { - idiopathic intracranial hypertension }\end{array}$ \\
\hline Psychosis & $\begin{array}{l}\text { - vasculitis } \\
\text { - SLE } \\
\text { - GM2 gangliosidosis } \\
\text { - Susac syndrome } \\
\text { - corticosteroid therapy }\end{array}$ \\
\hline Cranial neuropathy & $\begin{array}{l}\text { - neuroborelliosis } \\
\text { - neurosarcoidosis } \\
\text { - Bechet disease }\end{array}$ \\
\hline Visual loss & $\begin{array}{l}\text { - LHON } \\
\text { - Psychogenic }\end{array}$ \\
\hline Recurrent optic neuropathy & $\begin{array}{l}\text { - NMO } \\
\text { - LHON } \\
\text { - CRION }\end{array}$ \\
\hline retinopathy & $\begin{array}{l}\text { - Susac syndrome } \\
\text { - Mitochondrial encephalopathy }\end{array}$ \\
\hline Peripheral neuropathy & $\begin{array}{l}\text { - Charcot Marie-Tooth disease } \\
\text { - neuroborelliosis } \\
\text { - Guillain-Barré Syndrome }\end{array}$ \\
\hline $\begin{array}{l}\text { Progressive/relapsing } \\
\text { encephalopathy }\end{array}$ & $\begin{array}{l}\text { - Leukodystrophies } \\
\text { - Mitochondrial encephalopathy } \\
\text { - CADASIL }\end{array}$ \\
\hline Spastic paraplegia & $\begin{array}{l}\text { - NMO } \\
\text { - Tumor, vascular disorders } \\
\text { - SLE } \\
\text { - neurosarcoidosis } \\
\text { - Hereditary spastic paraplegia }\end{array}$ \\
\hline
\end{tabular}

SLE systemic lupus erythematosus, NMO neuromyelitis optica, LHON Leber hereditary optic neuropathy, CRION, chronic inflammatory optic neuropathy, CADASIL cerebral autosomal dominant arteriopathy with subcortical infarcts and leukoencephalopathy

Table 4 Diagnostic alternatives in relation to clinical evolution (from ref [1], modified)

\begin{tabular}{ll}
\hline ONSET & CONSIDER also \\
\hline Hyperacute & - Vascular disorders \\
& - Trauma \\
& - Toxic/infectious aetiologies \\
Acute or subacute & - Infectious aetiologies \\
& - Vascular/reumatological diseases \\
& - Malignancies \\
& - Macrophage-activation syndrome \\
Insidious, progressive & - Inherited metabolic disorders \\
& - Nutritional deficiencies (B12) \\
& - Vascular disorders \\
\hline
\end{tabular}

protein, proteolipid protein, myelin-associated oligodendrocyte basic glycoprotein and alpha-B-crystallin; by contrast, IgM autoantibodies targeting myelin basic protein, proteolipid protein, myelin-associated oligodendrocyte basic glycoprotein and oligodendrocyte-specific protein resulted associated to MS.

MRI, with the technique of susceptibility-weighted imaging, can also help discriminate ADEM from pedMS [77].

Antibodies (Abs) to myelin oligodendrocytes glycoprotein (anti MOG Abs) have been detected in patients with ADEM, ADEM followed by attacks of optic neuritis, recurrent optic neuritis, transverse myelitis, ADS and could define a particular subset of patients with ADS [78-83]. They were present in about $35 \%$ of cases in a large cohort of patients with ADS, across all its clinical phenotypes [78]; anti-MOG positive patients rarely showed CSF oligoclonal bands (OBs) and MRI abnormalities, and had a lower risk of progression to MS after 1 year (13\% vs $38 \%)$. In this study the risk of MS in the follow up was 4 fold higher in negative vs positive antiMOG Abs patients, particularly if positive for CSF OBs. Other 2 studies have found anti-MOG Abs in about $18 \%$ of patients with ADS, in some NMO seronegative patients, in patients with ADEM/encephalopathy and in subjects with isolated $\mathrm{ON}[81,82]$. So far, anti-MOG positive patients seem to have a distinct clinical phenotype, with lower progression to MS.

A complete review on autoantibodies in ADS was published in a recent issue of this journal [83].

CSF examination provides meaningful data for differential diagnosis. OBs are rarely observed in conditions such as ADEM and NMO, that more frequently show increased cells pleocytosis. Determination of lactate and lactate/pyruvate ratio is recommended if suspicion of mitochondrial encephalopathy, CSF culture, viral/bacterial antibobies, cytology if suspicion of infections, neoplasms [75].

CSF analysis can show an increased white blood cells count, especially in children [84].

Whilst OBs are detected in more than $90 \%$ of adults with MS, they are less frequent in patients with ped-MS (in $40-70 \%$ of cases), particularly in children [2].

Two recent studies, one including patients with $\mathrm{ON}$ at presentation, the other one including patients with ADS, have shown that OBs are linked to a higher risk of subsequent MS, in addition and independently from the presence of lesions at brain MRI [72, 73].

As already stated, brain MRI has an irreplaceable role in diagnosis and prognosis, but it also provides helpful information for differential diagnosis. Cases of transverse myelitis, spinal infarction, acute disseminated encephalomyelitis, fever-induced refractory epileptic encephalopathy in school-aged children, small-vessel vasculitis, Griscelli 
Table 5 Criteria to differentiate ADEM from MS (from ref. [29] modified)

\begin{tabular}{|c|c|c|}
\hline Typical features & ADEM & MS \\
\hline Demographic & $\begin{array}{l}\text { More frequent in young subjects } \\
(<10-12 \text { years); no gender } \\
\text { predilection }\end{array}$ & $\begin{array}{l}\text { More frequent in adolescents; } \\
\text { girls more affected than boys }\end{array}$ \\
\hline Prior flu-like illness & Very frequent & Variable \\
\hline \multicolumn{3}{|l|}{ Symptoms } \\
\hline - Seizures & Variable & Rare \\
\hline - Encephalopathy & Required in definition & Rare early in the disease \\
\hline - Discrete event & $\begin{array}{l}\text { A single event can fluctuate over } \\
\text { the course of } 12 \text { weeks }\end{array}$ & $\begin{array}{l}\text { Discrete events separated by } \\
\text { at least } 4 \text { weeks }\end{array}$ \\
\hline \multicolumn{3}{|l|}{ MRI: } \\
\hline - Large lesions involving gray and white matter & Frequent & Rare \\
\hline - Enhancement & Frequent & Frequent \\
\hline - Longitudinal MRI findings & $\begin{array}{l}\text { Lesions typically either resolve or } \\
\text { show only residual findings }\end{array}$ & $\begin{array}{l}\text { Typically associated with } \\
\text { development of new lesions }\end{array}$ \\
\hline \multicolumn{3}{|l|}{ CSF } \\
\hline - Pleocytosis & Variable & $\begin{array}{l}\text { rare, white blood cell count } \\
\text { almost always }<50\end{array}$ \\
\hline - Oligoclonal bands & Variable & Frequent \\
\hline
\end{tabular}

syndrome type 2, cysticercosis, vitamin B12 deficiency and chronic relapsing inflammatory optic neuropathy have been described highlighting the unusual clinical and radiologic features that should be considered in differential diagnosis of ped-MS [85]. Other relevant red flags are: absence of T2 weighted lesions, failure to document T2 lesion accrual, presence of meningeal gadolinium enhancement, visible cortical lesions, focal cortical volume loss, long extending spinal cord lesions in spinal MRI [2]. In relation to the prevalent site of white matter involvement or the selective involvement of white matter tracts, or to spinal cord involvement, other alternative conditions should be considered [74] (Table 6).

Extensive lesions, greater than 3 spinal cord segments, are more likely related to ADEM or NMO.

\section{MRI: a true distinctive pattern in ped-MS?}

Brain MRI offers the possibility to study in vivo the characteristics of lesions, their structure and evolution, with insights on the pathological substratum. Studies with conventional and non-conventional MRI have shown some peculiar aspects of lesions of ped-MS patients:

- lesions are more frequently found in the cerebellum/ brainstem [86, 87], leading to an impaired ageexpected cerebellar growth [88];

- lesions have more pronounced inflammatory aspects suggested by the large edematous aspect of lesions, and by the frequent enhancement after gadolinium injection, especially in children, with a frequent capability to recover and disappear with time [86, 87, 89, 90];
- lesions are less destructive and/or have a greater reparative capacity, as they show a greater recovery of T1 intensity with time [86];

- studies with non-conventional MRI have shown a less severe structural damage and a better capability to compensate brain damage and to promote remyelination [91-95];

- gray matter involvement is lower and cortical lesions are less, at least initially, in pediatric compared to adult MS, but thalamus is typically involved bilaterally [96-101];

- lesions at brain MRI correlate with CD and clinical outcome [52, 97];

- demyelinating lesions have a severe effect on brain development, reducing brain volume and skull size [102, 103];

\section{Pathobiology and pathophysiology: common risk} factors for a fairly rare disease?

With respect to adult MS, the pediatric form offers the unique possibility to better explore environmental factors associated to the risk of developing MS and relapses, as confounding factors occurring along the course of MS are less present [104].

Studies in children and adolescents have pointed out that an increased risk of MS is related to previous exposure to passive smoking [105], to Epstein-Barr virus (demonstrated by two independent studies [106, 107]), and to BMI [108]. Obesity in childhood or at 20 years of age has been confirmed as a risk factor in a cohort of 1235 adult MS patients [109], and further increases the risk in patients with previous EBV infection [110] and 
Table 6 Diagnostic alternatives in relation to the pattern of lesions on brain MRI (from ref. [74], modified)

\begin{tabular}{|c|c|c|}
\hline Region of white matter involvement & Clinical conditions & $\begin{array}{l}\text { Letter: It permits to identify } \\
\text { the occurrence of the same } \\
\text { disease in other rows }\end{array}$ \\
\hline Frontal & $\begin{array}{l}\text { - Alexander disease } \\
\text { - metachromatic leukodystrophy } \\
\text { - megalencephalic leukoencephalopathy with subcortical cysts } \\
\text { - variant adrenoleukodystrophy }\end{array}$ & $\begin{array}{l}a \\
b\end{array}$ \\
\hline Parieto-occipital & $\begin{array}{l}\text { - Adrenoleukodystrophy } \\
\text { - Krabbe disease } \\
\text { - paroxisomal disorders } \\
\text { - mitochondrial disorders }\end{array}$ & $\begin{array}{l}c \\
d \\
e\end{array}$ \\
\hline Temporal & $\begin{array}{l}\text { - CADASIL } \\
\text { - Aicardi-Goutières syndrome } \\
\text { - Cytomegalovirus encephalitis } \\
\text { - megalencephalic leukoencephalopathy with subcortical cysts }\end{array}$ & $\begin{array}{l}f \\
g\end{array}$ \\
\hline Periventricular & $\begin{array}{l}\text { - Hemophagocitic lymphohisiocytosis } \\
\text { - metachromatic leukodystrophy } \\
\text { - leukoencephalopathy with brainstem-spinal cord involvement } \\
\text { and elevated lactate } \\
\text { - vanishing white matter disease } \\
\text { - CADASIL }\end{array}$ & $\begin{array}{l}b \\
h \\
f\end{array}$ \\
\hline Basal ganglia & $\begin{array}{l}\text { - mitochondrial disorders } \\
\text { - biotinidase deficiency } \\
\text { - Wilson disease } \\
\text { - Bilateral striatal necrosis } \\
\text { - Biotin-responsive basal ganglia disease } \\
\text { - Aicardi-Goutières syndrome }\end{array}$ & $\begin{array}{l}\text { e } \\
\text { g }\end{array}$ \\
\hline Thalamus & $\begin{array}{l}\text { - Malignancies } \\
\text { - Hepatic encephalopathy } \\
\text { - Acute necrotizing encephalopathy } \\
\text { - leukoencephalopathy with thalamus and brainstem involvement } \\
\text { and elevated lactate } \\
\text { - Fabry disease }\end{array}$ & $\begin{array}{l}i \\
\mathrm{~m} \\
\mathrm{n}\end{array}$ \\
\hline Brainstem & $\begin{array}{l}\text { - Malignancies } \\
\text { - Rhombencephalitis } \\
\text { - Tuberculosis } \\
\text { - Bechet disease } \\
\text { - Alexander disease } \\
\text { - leukoencephalopathy with thalamus and brainstem involvement } \\
\text { and elevated lactate } \\
\text { - leukoencephalopathy with brainstem-spinal cord involvement } \\
\text { and elevated lactate }\end{array}$ & $\begin{array}{l}\mathrm{i} \\
\mathrm{a} \\
\mathrm{m} \\
\mathrm{h}\end{array}$ \\
\hline \multicolumn{3}{|l|}{ Involvement of white matter tracts } \\
\hline Corticospinal & $\begin{array}{l}\text { - adrenoleukodystrophy } \\
\text { - adrenomyeloneuropathy } \\
\text { - Krabbe disease } \\
\text { - adult-onset leukoencephalopathy with axonal spheroids and } \\
\text { pigmental glia }\end{array}$ & $\begin{array}{l}c \\
d\end{array}$ \\
\hline Dorsal column & $\begin{array}{l}\text { - leukoencephalopathy with thalamus and brainstem involvement } \\
\text { and elevated lactate } \\
\text { - vitamin B12/copper deficiency }\end{array}$ & $\mathrm{m}$ \\
\hline Subcortical U-fibers & $\begin{array}{l}\text { - Canavan disease } \\
\text { - Kearns-Sayre syndrome }\end{array}$ & \\
\hline External capsule/insula & $\begin{array}{l}\text { - Acute necrotizing encephalopathy } \\
\text { - CADASIL }\end{array}$ & I \\
\hline Corpus callosum & $\begin{array}{l}\text { - Susac syndrome, } \\
\text { - Krabbe disease }\end{array}$ & $\mathrm{d}$ \\
\hline \multicolumn{3}{|l|}{ Spinal cord } \\
\hline Hyperintensity & $\begin{array}{l}\text { - Sarcoidosis } \\
\text { - Systemic lupus erythematosus } \\
\text { - CLIPPERS (chronic lymphocytic inflammation with pontine perivascular } \\
\text { enhancement responsive to steroids) } \\
\text { - infections }\end{array}$ & \\
\hline Atrophy & $\begin{array}{l}\text { - leukoencephalopathy with thalamus and brainstem involvement and } \\
\text { elevated lactate } \\
\text { - Alexander disease } \\
\text { - adult polyglucosan body disease }\end{array}$ & $\begin{array}{l}\mathrm{m} \\
\mathrm{a}\end{array}$ \\
\hline
\end{tabular}


carrying the HLA-DRB1*15 allele [111]. Diet has been investigated as a possible risk factor: in this context the role of salt-intake has been investigated in a recent publication, but no correlation was found [112].

Low levels of vitamin D were linked to an increased risk of MS in two independent studies. However the supplementation with vitamin D has only a marginal effect in adult MS patients whose increase in blood level is lower compared with controls [113].

Life-style and physical activity should be included among modifiable risk factors. A reduced physical activity per se [61], or as consequence of factors related to MS such as ongoing disease activity, perceived limitations, depression and fatigue [60], has found to be related a higher level of disease activity (more relapses, more MRI T2 lesions), suggesting a potential protective effect of strenuous physical activity in this population. This finding has lead to develop an agenda for promoting further studies on this topic, and to plan interventions for enhancing physical activity in subjects with ped-MS [61]. Surprisingly, there is a strong analogy with the approach to cognitive dysfunction management: both strategies have the objective to reinforce the physical and mental background (functional reserve) to better protect from brain loss and to improve brain plasticity.

Hormonal changes during puberty can also facilitate MS onset as already discussed in Background section. Female sex involves a risk of MS about twice higher in patients with ADS [106].

The genetic background has a well known important role to determine the risk of MS. HLA-DRB1 alleles were characterized in 266 children presenting with ADS, 64 of them with a final diagnosis of MS [114]: children harboring DRB1*15 alleles were more likely to be diagnosed with $\mathrm{MS}(\mathrm{OR}=2.7)$, supporting a fundamental similar genetic contribution to MS risk in both pediatricand adult-onset disease. In a large-scale genome-wide association study 57 genetic risk loci have been identified in adult patients with MS: the same pattern has been found in a cohort of 53 MS patients from a cohort of 188 children with ADS, indicating that the combined effect of 57 SNPs exceeded the effect of HLA-DRB1*15 alone [115], conferring an increased susceptibility to pediatric-onset MS compared to monophasic ADS.

The genetic predisposition further enhances the risk of developing MS in combination with other factors such as obesity, previous infections, vitamin D status $[110,111,116]$, the latter factor also with a possible effect on disease activity [117].

At present it is not known whether ped-MS patients have a higher genetic burden, studies are ongoing to better evaluate this aspect.

Many alterations of the immune response have been documented in ped-MS, with findings not so far different from those observed in adult MS in spite of the more immature immune system $[2,118-120]$.

To conclude, the genetic background plays an important role, combined with physical and environmental factors, to determine the risk of MS (see also Table 7), with pathogenetic mechanisms not so different form the adult form.

\section{Treatment: borrowing from adulthood, but still many obstacles to overcome}

Differently from adult form, medications for MS have not been tested in children and adolescents with randomized controlled trials. Data are only available from open label observational studies, providing information on safety and, in some extent, on effectiveness. It is desirable to better evaluate the effects of medications in pediatric MS patients [121], nevertheless many factors limit the possibility to perform clinical trials in this population [122]:

- the use of placebo, required by Regulatory Authorities in some studies,

- the difficulty to propose a trial with a medication that has been already approved for adults,

- the difficulty, in some cases, to obtain the informed consent,

- the difficulty to have access to hospital, with loss of days of school or work (for parents),

- the relative rarity of ped-MS,

- the competition among drugs now available in the market.

In spite of their intrinsic limitations, observational studies have provided data on the effect of some first and second line disease modifying drugs (DMDs); their indications and limitations have been defined in two documents of experts [123, 124].

- For the treatment of acute attacks high dose corticosteroids are recommended (Methylprednisolone $10-40 \mathrm{mg} / \mathrm{kg}$ e.v. for 3-5 consecutive days). For severe cases with poor recovery in spite of corticosteroids, plasma exchange can be considered.

- To prevent relapses and progression the use of DMDs is strongly recommended. IFNB-1a and Glatiramer acetate are standard treatment, as used for many years without signals of consistent adverse events [124-126]. A common and shared approach is summarized in Fig. 1 (ref 124, modified).

- Among second line therapies, Natalizumab has been tested in many cohorts of patients with less than 18 years; it is an option for subjects with a very active evolution or no response to IFNB-1a or GA 
Table 7 Factors related to the risk of developing MS in children and adolescents

\begin{tabular}{|c|c|c|c|}
\hline Author & Study population & Risk factor & Change in risk \\
\hline Langer-Gould et al. & n. 75 , MS onset $<18$ years & BMI & $\begin{array}{l}\text { - Overweight x } 1.58 \\
\text { - Moderately obese x } 1.78 \\
\text { - Extremely obese x } 3.76\end{array}$ \\
\hline Mikaeloff et al. & n.90, MS onset 10 to $<16$ years & Passive smoking & $\times 2.49$ \\
\hline Banwell et al. & n. 49 , MS onset $<16$ years & Remote EBV infection & $\times 2.58$ \\
\hline Waubant et al. & n. 189 , MS onset $<18$ years & Remote EBV infection & $\times 3.72$ \\
\hline Disanto et al. & n. 64 , MS onset $<16$ years & $\geq 1$ HLA-DRB1 alleles & $\times 3.2$ \\
\hline McDonald et al. & n. 170 , MS onset $<18$ years & Salt intake & No effect \\
\hline Banwell et al. & n. 63 , MS onset $<16$ years & Vitamin D increase + $10 \mathrm{nmol} / \mathrm{L}$ & $10 \%$ reduction \\
\hline Monry et al. & n. 110, MS onset $\leq 18$ years & Vitamin D increase + $10 \mathrm{nmol} / \mathrm{L}$ & $30 \%$ reduction \\
\hline Waubant et al. & n. 189 , MS onset $<18$ years & VCM seropositivity & $73 \%$ reduction \\
\hline
\end{tabular}

[123, 124, 127-130]. A limitation in its use is represented by the risk of a rare but severe adverse events, the occurrence of progressive multifocal leukoencephalopathy (PML) due to reactivation of JCV virus, however this risk can be properly assessed checking anti-JCV antibodies [121]: the risk of PML increases closely with the antibodies titre and the duration of exposure to Natatizumab. In patients negative for anti-JCV antibodies the risk is close to 0 . Natalizumab has shown a very strong effect in reducing disease activity and putting patients in the condition of NEDA (No Evidence of Disease Activity - patients free from relapses, disease progression, $\mathrm{T} 2$ and $\mathrm{Gd}+$ lesions at brain MRI) in the large majority of cases and for a long time [130].

- Trials are ongoing testing the effect new oral medications [129], with different study design and different endpoints: i) Fingolimod (PARADIGMS study) in a double blind trial vs an active comparator (this trial has recently closed the enrollment of patients), having annualized relapse rate as primary endpoint ii) Dimetylfumarate in a single blind controlled study vs active comparator (CONNECT Study), evaluating the proportion of patients free of new or newly enlarging T2 lesions iii) Teriflunomide in a double blind trial vs placebo having the time to first relapse as primary endpoint (TERIKIDS Study).

Fingolimod and Dimetylfumarate have been evaluated in two small observational trials $[131,132]$ : they resulted well tolerated, but data are not sufficient for long term assessment of effectiveness and safety.

Cyclophosphamide, rituximab, mitoxantrone could be used in selected cases with aggressive MS. Alemtuzumab

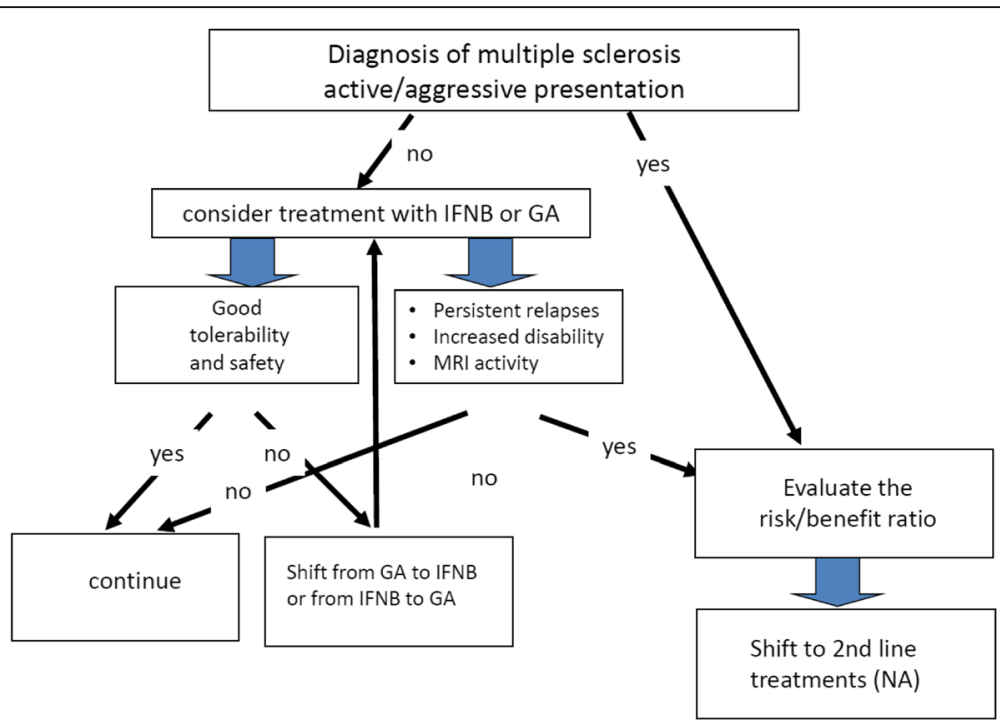

Fig. 1 Diagram showing the main steps in the treatment of pediatric multiple sclerosis (MS) 
has been recently approved for adults with active MS [121, 123, 124], hemopoietic stems cells transplantation [133] is proposed for active non-responder patients: however data are not available in children and adolescents with MS.

As already discussed, diagnosis of MS per se as well as the possible physical disability have a strong psychological effect on patients, their parents and family. Model of care should be centered on patients and their families, in specialized centers involving neurologists expert of MS, pediatricians or pediatric neurologists, specialized nurses, psychologists, social workers and specialists of rehabilitative medicine, as highlighted in a recent document of the IPMSSG [134].

The knowledge of a protective role of cognitive reserve and the evidence that physical activity improves brain functioning opens new perspectives in the field of rehabilitation.

\section{Conclusions}

There is large body of evidence that MS evolution is age-dependent, more relapsing in young subjects, more progressive in older ones, with a different speed to progress [135].

In ped-MS the basic pathophysiological findings are similar to those of the adult form, but differently modulated due to the immaturity of the nervous and immunological systems.

Some aspects seem to be peculiar of ped-MS:

- clinical manifestations are similar in adolescents and adults with MS; however, in younger subjects male to female ratio tends to be $1: 1$, with frequent brainstem/cerebellar involvement and an acute polysymptomatic/ADEM-like onset;

- the course is relapsing-remitting in the large majority of patients, with an high relapse rate;
- the interval to reach mild or severe disability is more prolonged but the age is lower in ped-MS patients compared to adults;

- the frequency of cognitive dysfunction is relatively high, with a quick deterioration but also the capability to recover partially in the long-term follow-up;

- diagnostic criteria can be applied to patients with less than 18 years, but with limitations for subjects with less than 12 years and ADEM-like onset;

- the approach in differential diagnosis is particular complex and many disorders with clinical manifestations in the pediatric age must be considered: in this context it is important to pay attention to clinical, MRI and CSF red flags;

- anti-MOG Ab syndrome has been recently identified and should be carefully considered in patients with ADS;

- CSF OBs are less frequent in ped-MS patients, their presence in patients with ADS being strongly correlated to risk of MS;

- MRI is fundamental for diagnosis and prognosis;

- the pattern of MRI has some peculiar aspects in ped-MS patients: i) the classic diagnostic criteria cannot be fulfilled, ii) lesion load is more relevant, iii) lesions more frequently involve the brainstem/ cerebellum, have a more pronounced inflammatory pattern, iii) lesions can disappear with time, less frequently evolve to T1 hypo intense lesions, indicating less structural damage, iiii) lesions are less destructive, and have enhanced capability to recover with time;

- ped-MS has a more pronounced inflammatory pattern (as suggested by clinical evolution predominant RR evolution with high relapse rateand MRI data), nevertheless axonal damage is also considerable [136].

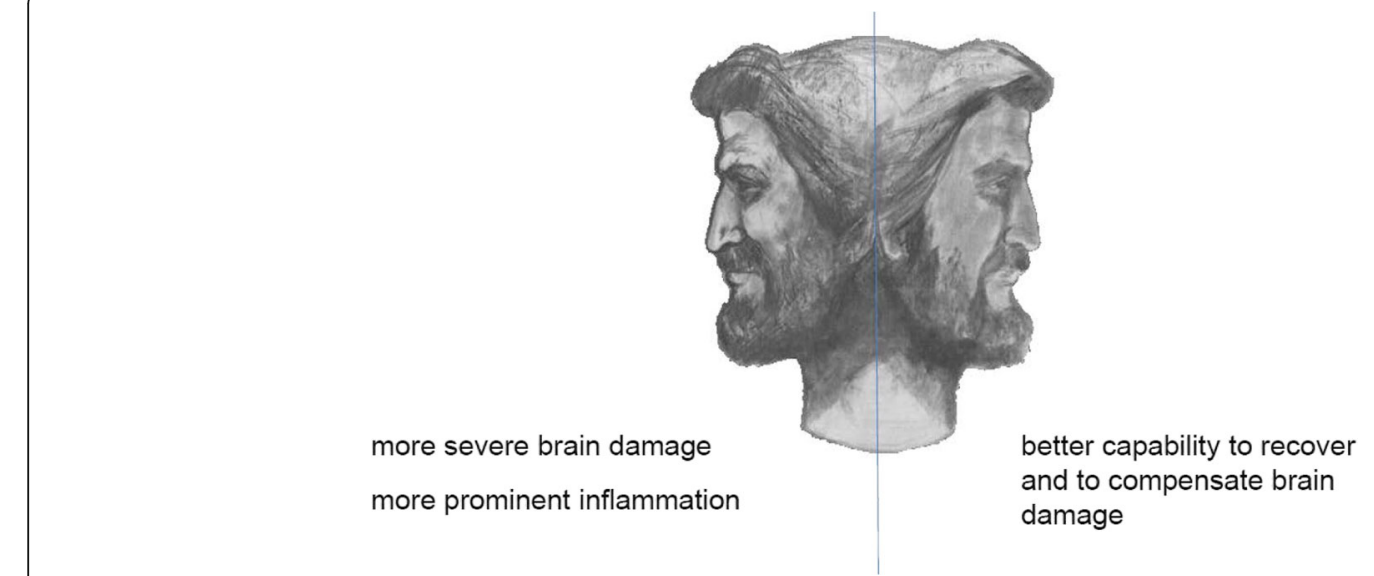

Fig. 2 pediatric MS: more or less benign with respect to the adult form? 
Some findings such as the high relapse rate, the acute onset with severe symptoms in some patients, the presence of cognitive dysfunction, the lower age to reach mild and severe disability, the effect of lesions on brain tissue and skull size are compatible with a more severe evolution.

On the contrary some other findings, such as the longer interval to reach $\mathrm{mid} /$ severe disability, the capability of the brain to recover and compensate brain damage, seem to suggest a more favorable evolution.

These findings lead to the conclusion that ped-MS is a more severe disease, compared to the adult form, but this higher severity is mitigated by the higher capability of the brain to compensate brain damage and to partially recover with time (Fig. 2).

\section{Acknowledgements \\ None. \\ Funding \\ None. \\ Availability of data and materials \\ Not applicable.}

\section{Authors' contributions}

Dr. AG conceived the work, collected and revised literature data, wrote the first and the final version of the manuscript. Dr. DB and Dr. MZ helped to collect and revise literature data, revised and contributed to the final version of the manuscript. Prof. GC critically revised the manuscript. All authors have read the manuscript, the paper has not been previously published and is not under simultaneous consideration by another journal. No ghost writing by authors not named on the list. All authors read and approved the final manuscript.

\section{Competing interests}

Angelo Ghezzi serves on scientific advisory boards for Merck Serono and Teva Pharmaceutical Industries Itd; received honoraria for speaking form Merck Serono, Biogen Idec, Bayer Schering Pharma and Novartis; serves as a consultant for Novartis, receives research support from Sanofi Aventis, Biogen Idec and Merck Serono.

Damiano Baroncini received honoraria from Almirall for creation of editorial publication and travel grants for participation to national and international congresses/courses from Genzyme, Merck and Novartis.

Mauro Zaffaroni has received honoraria for consulting or lecturing or travel grants for attending meetings from Almirall, Biogen Idec, Genzyme, Medtronic, Merck Serono, Novartis and Teva.

Giancarlo Comi serves on scientific advisory boards for Bayer Schering Pharma, Merck Serono, Teva Pharmaceutical Industries Ltd, Sanofi Aventis, Novartis and Biogen-Idec; has received speaker honoraria from Teva Pharmaceutical Industries Ltd, Sanofi Aventis, Serono Sumposia International Foundation, Biogen-ldec, Merck Serono, Novartis, Bayer Schering and Sanofi Aventis.

\section{Consent for publication}

Not applicable.

Ethics approval and consent to participate

Not applicable.

\section{Publisher's Note}

Springer Nature remains neutral with regard to jurisdictional claims in published maps and institutional affiliations.

\section{Author details}

'Centro Studi Sclerosi Multipla, ASST Valleolona, Via Pastori 4, Gallarate 21013, Italy. ${ }^{2}$ Department of Neurology, Scientific Institute H.S. Raffaele, Milan, Italy.

Received: 30 January 2017 Accepted: 30 March 2017

Published online: 08 May 2017

\section{References}

1. Banwell B, Ghezzi A, Bar-Or A, Mikaeloff Y, Tardieu M. Multiple sclerosis in children: clinical diagnosis, therapeutic strategies, and future directions. Lancet Neurol. 2007:6:887-902.

2. Waldman A, Ghezzi A, Bar-Or A, Mikaeloff Y, Tardieu M, Banwell B. Multiple sclerosis in children: an update on clinical diagnosis, therapeutic strategies, and research. Lancet Neurol. 2014;13:936-48.

3. Krupp LB, Tardieu M, Amato MP, et al. International Pediatric Multiple Sclerosis Study Group criteria for pediatric multiple sclerosis and immunemediated central nervous system demyelinating disorders: revisions to the 2007 definitions. Mult Scler. 2013;19:1261-7.

4. Ketelslegers IA, Catsman-Berrevoets CE, Neuteboom RF, et al. Incidence of acquired demyelinating syndromes of the CNS in Dutch children: a nationwide study. J Neurol. 2012;259:1929-35.

5. Langer-Gould A, Zhang JL, Chung J, Yeung Y, Waubant E, Yao J. Incidence of acquired CNS demyelinating syndromes in a multiethnic cohort of children. Neurology. 2011:77:1143-8.

6. Banwell B, Kennedy J, Sadovnick D, et al. Incidence of acquired demyelination of the CNS in Canadian children. Neurology. 2009:72:232-9.

7. Dell'Avvento S, Sotgiu MA, Manca S, Sotgiu G, Sotgiu S. Epidemiology of multiple sclerosis in the pediatric population of Sardinia, Italy. Eur J Pediatr. 2016;175:19-29.

8. Reinhardt K, Weiss S, Rosenbauer J, Gartner J, von Kries R. Multiple sclerosis in children and adolescents: incidence and clinical picture - new insights from the nationwide German surveillance (2009-2011). Eur J Neurol. 2014:21:654-9.

9. Langille MM, Islam T, Burnett M, Amezcua L. Clinical characteristics of pediatric-onset and adult-onset multiple sclerosis in hispanic americans. J Child Neurol. 2016;31:1068-73.

10. Alroughani R, Ahmed SF, Al-Hashel J. Pediatric-onset multiple sclerosis disease progression in Kuwait: a retrospective analysis. Pediatr Neurol. 2015:53:508-12.

11. Alroughani R, Akhtar S, Ahmed SF, Behbehani R, Al-Abkal J, Al-Hashel J. Incidence and prevalence of pediatric onset multiple sclerosis in Kuwait: 1994-2013. J Neurol Sci. 2015;353:107-10.

12. Etemadifar $\mathrm{M}$, Nourian $\mathrm{SM}$, Nourian $\mathrm{N}$, et al. Early-onset multiple sclerosis in Isfahan, Iran: report of the demographic and clinical features of 221 patients. J Child Neurol. 2016;31:932-7.

13. Fragoso YD, Ferreira ML, Morales Nde M, et al. Multiple sclerosis starting before the age of 18 years: the Brazilian experience. Arq Neuropsiquiatr. 2013;71:783-7.

14. Araqi-Houssaini A, Dany F, Sekkat Z, et al. Pediatric multiple sclerosis: is it different from the adult form? Rev Neurol. 2014;170:531-5.

15. Kim YM, Kim HY, Cho MJ, et al. Optic neuritis in Korean children: Low risk of subsequent multiple sclerosis. Pediatr Neurol. 2015;53:221-5.

16. Yamaguchi $Y$, Torisu $H$, Kira R, et al. A nationwide survey of pediatric acquired demyelinating syndromes in Japan. Neurology. 2016;87:2006-15.

17. Derle E, Kurne AT, Konuskan B, Karabudak R, Anlar B. Unfavorable outcome of pediatric onset multiple sclerosis: Follow-up in the pediatric and adult neurology departments of one referral center, in Turkey. Mult Scler Relat Disord. 2016;9:1-4.

18. Tanuja Chitnis and Daniela Pohl, On behalf of the International Pediatric MS Study Group (IPMSSG) Steering Committee Pediatric demyelinating disorders: Global updates, controversies, and future directions Neurology 2016;1-S116.

19. Ghezzi A. Clinical characteristics of multiple sclerosis with early onset. Neurol Sci. 2004;25(Suppl 4):S336-9.

20. Waldman A, Ness J, Pohl D, et al. Pediatric multiple sclerosis: Clinical features and outcome. Neurology. 2016;87:S74-81.

21. Huppke B, Ellenberger D, Rosewich H, Friede T, Gartner J, Huppke P. Clinical presentation of pediatric multiple sclerosis before puberty. Eur J Neurol. 2014;21:441-6.

22. Duquette P, Murray TJ, Pleines J, et al. Multiple sclerosis in childhood: clinical profile in 125 patients. J Pediatr. 1987;111:359-63. 
23. Ruggieri M, Polizzi A, Pavone L, Grimaldi LM. Multiple sclerosis in children under 6 years of age. Neurology. 1999;53:478-84.

24. Ruggieri M, lannetti P, Polizzi A, Pavone L, Grimaldi LM, Italian Society of Paediatric Neurology Study Group on Childhood Multiple S. Multiple sclerosis in children under 10 years of age. Neurol Sci. 2004;25(Suppl 4):S326-35.

25. Haliloglu G, Anlar B, Aysun S, et al. Gender prevalence in childhood multiple sclerosis and myasthenia gravis. J Child Neurol. 2002;17:390-2.

26. Ahn JJ, O'Mahony J, Moshkova M, et al. Puberty in females enhances the risk of an outcome of multiple sclerosis in children and the development of central nervous system autoimmunity in mice. Mult Scler. 2015;21:735-48.

27. Chitnis T. Role of puberty in multiple sclerosis risk and course. Clin Immunol (Orlando, Fla). 2013;149:192-200.

28. Lulu S, Graves J, Waubant E. Menarche increases relapse risk in pediatric multiple sclerosis. Mult Scler. 2016;22:193-200.

29. Krupp LB, Banwell B, Tenembaum S, International Pediatric MSSG Consensus definitions proposed for pediatric multiple sclerosis and related disorders. Neurology. 2007;68:S7-12

30. Tenembaum S, Chitnis T, Nakashima I, et al. Neuromyelitis optica spectrum disorders in children and adolescents. Neurology. 2016;87:S59-66.

31. Benson LA, Healy BC, Gorman MP, et al. Elevated relapse rates in pediatric compared to adult MS persist for at least 6 years. Mult Scler Relat Disord. 2014;3:186-93.

32. Gorman MP, Healy BC, Polgar-Turcsanyi M, Chitnis T. Increased relapse rate in pediatric-onset compared with adult-onset multiple sclerosis. Arch Neurol. 2009;66:54-9.

33. Boiko A, Vorobeychik G, Paty D, Devonshire V, Sadovnick D, University of British Columbia MSCN. Early onset multiple sclerosis: a longitudinal study. Neurology. 2002;59:1006-10.

34. Simone IL, Carrara D, Tortorella C, et al. Course and prognosis in early-onset MS: comparison with adult-onset forms. Neurology. 2002;59:1922-8.

35. Renoux C, Vukusic $\mathrm{S}$, Mikaeloff $\mathrm{Y}$, et al. Natural history of multiple sclerosis with childhood onset. N Engl J Med. 2007:356:2603-13.

36. Cardoso M, Olmo NR, Fragoso YD. Systematic review of cognitive dysfunction in pediatric and juvenile multiple sclerosis. Pediatr Neurol. 2015;53:287-92.

37. Suppiej A, Cainelli E. Cognitive dysfunction in pediatric multiple sclerosis. Neuropsychiatr Dis Treat. 2014;10:1385-92.

38. Amato MP, Krupp LB, Charvet LE, Penner I, Till C. Pediatric multiple sclerosis: Cognition and mood. Neurology. 2016;87:582-7.

39. Amato MP, Goretti B, Ghezzi A, et al. Cognitive and psychosocial features of childhood and juvenile MS. Neurology. 2008;70:1891-7.

40. Julian $L$, Serafin $D$, Charvet $L$, et al. Cognitive impairment occurs in children and adolescents with multiple sclerosis: results from a United States network. J Child Neurol. 2013;28:102-7.

41. Banwell BL, Anderson PE. The cognitive burden of multiple sclerosis in children. Neurology. 2005;64:891-4.

42. MacAllister WS, Belman AL, Milazzo M, et al. Cognitive functioning in children and adolescents with multiple sclerosis. Neurology. 2005;64:1422-5.

43. Baruch NF, O'Donnell EH, Glanz Bl, et al. Cognitive and patient-reported outcomes in adults with pediatric-onset multiple sclerosis. Mult Scler. 2016;22:354-61.

44. Charvet L, Cersosimo B, Schwarz C, Belman A, Krupp LB. Behavioral symptoms in pediatric multiple sclerosis: relation to fatigue and cognitive impairment. J Child Neurol. 2016;31:1062-7.

45. Holland AA, Graves D, Greenberg BM, Harder LL. Fatigue, emotional functioning, and executive dysfunction in pediatric multiple sclerosis. Child Neuropsychol. 2014:20:71-85.

46. Weisbrot D, Charvet L, Serafin D, et al. Psychiatric diagnoses and cognitive impairment in pediatric multiple sclerosis. Mult Scler. 2014;20:588-93.

47. Charvet LE, Cleary RE, Vazquez K, Belman AL, Krupp LB, MS USNfP. Social cognition in pediatric-onset multiple sclerosis (MS). Mult Scler. 2014;20:1478-84

48. Charvet LE, O'Donnell EH, Belman AL, et al. Longitudinal evaluation of cognitive functioning in pediatric multiple sclerosis: report from the US Pediatric Multiple Sclerosis Network. Mult Scler. 2014;20:1502-10.

49. Amato MP, Goretti B, Ghezzi A, et al. Neuropsychological features in childhood and juvenile multiple sclerosis: five-year follow-up. Neurology. 2014:83:1432-8

50. Amato MP, Goretti B, Ghezzi A, et al. Cognitive and psychosocial features in childhood and juvenile MS: two-year follow-up. Neurology. 2010;75:1134-40.
51. Till C, Racine N, Araujo D, et al. Changes in cognitive performance over a 1 -year period in children and adolescents with multiple sclerosis. Neuropsychology. 2013;27:210-9.

52. Maghzi AH, Revirajan N, Julian LJ, et al. Magnetic resonance imaging correlates of clinical outcomes in early multiple sclerosis. Mult Scler Relat Disord. 2014:3:720-7.

53. Rocca MA, Absinta M, Amato MP, et al. Posterior brain damage and cognitive impairment in pediatric multiple sclerosis. Neurology. 2014;82:1314-21.

54. Rocca MA, Morelli ME, Amato MP, et al. Regional hippocampal involvement and cognitive impairment in pediatric multiple sclerosis. Mult Scler. 2016;22:628-40.

55. Weier K, Till C, Fonov V, et al. Contribution of the cerebellum to cognitive performance in children and adolescents with multiple sclerosis. Mult Scler. 2016;22:599-607.

56. Pasto L, Portaccio E, Goretti $B$, et al. The cognitive reserve theory in the setting of pediatric-onset multiple sclerosis. Mult Scler. 2016;22:1741-9.

57. Krysko KM, O'Connor P. Quality of life, cognition and mood in adults with pediatric multiple sclerosis. Can J Neurol Sci. 2016:43:368-74.

58. Till C, Udler E, Ghassemi R, Narayanan S, Arnold DL, Banwell BL. Factors associated with emotional and behavioral outcomes in adolescents with multiple sclerosis. Mult Scler. 2012;18:1170-80.

59. Rocca MA, Absinta M, Ghezzi A, Moiola L, Comi G, Filippi M. Is a preserved functional reserve a mechanism limiting clinical impairment in pediatric MS patients? Hum Brain Mapp. 2009;30:2844-51.

60. Grover SA, Aubert-Broche B, Fetco D, et al. Lower physical activity is associated with higher disease burden in pediatric multiple sclerosis. Neurology. 2015;85:1663-9.

61. Yeh EA, Kinnett-Hopkins D, Grover SA, Motl RW. Physical activity and pediatric multiple sclerosis: Developing a research agenda. Mult Scler. 2015;21:1618-25.

62. Hubacher M, DeLuca J, Weber P, et al. Cognitive rehabilitation of working memory in juvenile multiple sclerosis-effects on cognitive functioning, functional MRI and network related connectivity. Restor Neurol Neurosci. 2015;33:713-25.

63. Charvet LE, Beekman R, Amadiume N, Belman AL, Krupp LB. The Symbol Digit Modalities Test is an effective cognitive screen in pediatric onset multiple sclerosis (MS). J Neurol Sci. 2014;341:79-84.

64. Portaccio E, Goretti B, Lori S, et al. The brief neuropsychological battery for children: a screening tool for cognitive impairment in childhood and juvenile multiple sclerosis. Mult Scler. 2009;15:620-6.

65. Polman CH, Reingold SC, Banwell B, et al. Diagnostic criteria for multiple sclerosis: 2010 revisions to the McDonald criteria. Ann Neurol. 2011;69:292-302.

66. Kornek B, Schmitl B, Vass K, et al. Evaluation of the 2010 McDonald multiple sclerosis criteria in children with a clinically isolated syndrome. Mult Scler. 2012;18:1768-74.

67. Sadaka Y, Verhey LH, Shroff MM, et al. 2010 McDonald criteria for diagnosing pediatric multiple sclerosis. Ann Neurol. 2012;72:211-23.

68. Hummel HM, Bruck W, Dreha-Kulaczewski S, Gartner J, Wuerfel J. Pediatric onset multiple sclerosis: McDonald criteria 2010 and the contribution of spinal cord MRI. Mult Scler. 2013;19:1330-5.

69. Verhey LH, Branson HM, Shroff MM, et al. MRI parameters for prediction of multiple sclerosis diagnosis in children with acute CNS demyelination: a prospective national cohort study. Lancet Neurol. 2011;10:1065-73.

70. Verhey LH, van Pelt-Gravesteijn ED, Ketelslegers IA, et al. Validation of MRI predictors of multiple sclerosis diagnosis in children with acute CNS demyelination. Mult Scler Relat Disord. 2013;2:193-9.

71. Bigi S, Marrie RA, Verhey L, Yeh EA, Banwell B. 2010 McDonald criteria in a pediatric cohort: is positivity at onset associated with a more aggressive multiple sclerosis course? Mult Scler. 2013;19:1359-62.

72. Heussinger N, Kontopantelis E, Gburek-Augustat J, et al. Oligoclonal bands predict multiple sclerosis in children with optic neuritis. Ann Neurol. 2015;77:1076-82.

73. Neuteboom RF, Boon M, Catsman Berrevoets CE, et al. Prognostic factors after a first attack of inflammatory CNS demyelination in children. Neurology. 2008;71:967-73.

74. Rostasy K, Bajer-Kornek B, Venkateswaran S, Hemingway C, Tardieu M. Differential diagnosis and evaluation in pediatric inflammatory demyelinating disorders. Neurology. 2016;87:S28-37.

75. O'Mahony J, Bar-Or A, Arnold DL, et al. Masquerades of acquired demyelination in children: experiences of a national demyelinating disease program. J Child Neurol. 2013;28:184-97. 
76. Van Haren K, Tomooka BH, Kidd BA, et al. Serum autoantibodies to myelin peptides distinguish acute disseminated encephalomyelitis from relapsingremitting multiple sclerosis. Mult Scler. 2013;19:1726-33.

77. Kelly JE, Mar S, D'Angelo G, Zhou G, Rajderkar D, Benzinger TL. Susceptibility-weighted imaging helps to discriminate pediatric multiple sclerosis from acute disseminated encephalomyelitis. Pediatr Neurol. 2015;52:36-41.

78. Hacohen Y, Absoud M, Deiva K, et al. Myelin oligodendrocyte glycoprotein antibodies are associated with a non-MS course in children. Neurol Neuroimmunol Neuroinflamm. 2015;2:e81.

79. Rostasy K, Mader S, Hennes EM, et al. Persisting myelin oligodendrocyte glycoprotein antibodies in aquaporin-4 antibody negative pediatric neuromyelitis optica. Mult Scler. 2013;19:1052-9.

80. Rostasy K, Mader S, Schanda K, et al. Anti-myelin oligodendrocyte glycoprotein antibodies in pediatric patients with optic neuritis. Arch Neurol. 2012;69:752-6.

81. Fernandez-Carbonell C, Vargas-Lowy D, Musallam A, et al. Clinical and MRI phenotype of children with MOG antibodies. Mult Scler. 2016;22:174-84.

82. Ketelslegers IA, Van Pelt DE, Bryde S, et al. Anti-MOG antibodies plead against MS diagnosis in an Acquired Demyelinating Syndromes cohort. Mult Scler. 2015;21:1513-20.

83. Armangue T, Yeshokumar A, Sepúlveda M, et al. Antibodies in acquired demyelinating disorders in children. Mult Scler Demyelinating Disord. 2016;1:5.

84. Chabas D, Ness J, Belman A, et al. Younger children with MS have a distinct CSF inflammatory profile at disease onset. Neurology. 2010;74:399-405.

85. O'Mahony J, Shroff M, Banwell B. Mimics and rare presentations of pediatric demyelination. Neuroimaging Clin N Am. 2013;23:321-36.

86. Ghassemi R, Narayanan S, Banwell B, et al. Quantitative determination of regional lesion volume and distribution in children and adults with relapsing-remitting multiple sclerosis. PLoS One. 2014;9:e85741.

87. Waubant E, Chabas D, Okuda DT, et al. Difference in disease burden and activity in pediatric patients on brain magnetic resonance imaging at time of multiple sclerosis onset vs adults. Arch Neurol. 2009;66:967-71.

88. Weier K, Fonov V, Aubert-Broche B, Arnold DL, Banwell B, Collins DL. Impaired growth of the cerebellum in pediatric-onset acquired CNS demyelinating disease. Mult Scler. 2016;22:1266-78.

89. Chabas D, Castillo-Trivino T, Mowry EM, Strober JB, Glenn OA, Waubant E. Vanishing MS T2-bright lesions before puberty: a distinct MRI phenotype? Neurology. 2008;71:1090-3.

90. Nunan-Saah J, Paulraj SR, Waubant E, Krupp LB, Gomez RG Neuropsychological correlates of multiple sclerosis across the lifespan. Mult Scler. 2015;21:1355-64.

91. Rocca MA, Valsasina $P$, Absinta M, et al. Intranetwork and internetwork functional connectivity abnormalities in pediatric multiple sclerosis. Hum Brain Mapp. 2014;35:4180-92.

92. Ghassemi R, Brown R, Banwell B, Narayanan S, Arnold DL, Canadian Pediatric Demyelinating Disease Study G. Quantitative Measurement of tissue damage and recovery within new T2w lesions in pediatric- and adult-onset multiple sclerosis. Mult Scler. 2015;21:718-25.

93. Rocca MA, Absinta M, Moiola L, et al. Functional and structural connectivity of the motor network in pediatric and adult-onset relapsing-remitting multiple sclerosis. Radiology. 2010;254:541-50.

94. Akbar N, Banwell B, Sled JG, et al. Brain activation patterns and cognitive processing speed in patients with pediatric-onset multiple sclerosis. J Clin Exp Neuropsychol. 2016;38:393-403.

95. Akbar N, Giorgio A, Till C, et al. Alterations in functional and structural connectivity in pediatric-onset multiple sclerosis. PLoS One. 2016;1 1:e0145906.

96. Donohue K, Cox JL, Dwyer MG, et al. No regional gray matter atrophy differences between pediatric- and adult-onset relapsing-remitting multiple sclerosis. J Neuroimaging. 2014;24:63-7.

97. Rocca MA, De Meo E, Amato MP, et al. Cognitive impairment in paediatric multiple sclerosis patients is not related to cortical lesions. Mult Scler. 2015:21:956-9.

98. Absinta M, Rocca MA, Moiola $L$, et al. Cortical lesions in children with multiple sclerosis. Neurology. 2011;76:910-3.

99. Tortorella P, Rocca MA, Mezzapesa DM, et al. MRI quantification of gray and white matter damage in patients with early-onset multiple sclerosis. J Neurol. 2006;253:903-7.
100. Brown RA, Narayanan S, Banwell B, Arnold DL, Canadian Pediatric Demyelinating Disease N. Magnetization transfer ratio recovery in new lesions decreases during adolescence in pediatric-onset multiple sclerosis patients. Neuroimage Clin. 2014;6:237-42.

101. Mesaros S, Rocca MA, Absinta M, et al. Evidence of thalamic gray matter loss in pediatric multiple sclerosis. Neurology. 2008;70:1107-12.

102. Aubert-Broche B, Fonov $V$, Narayanan S, et al. Onset of multiple sclerosis before adulthood leads to failure of age-expected brain growth. Neurology. 2014;83:2140-6.

103. Kerbrat A, Aubert-Broche B, Fonov V, et al. Reduced head and brain size for age and disproportionately smaller thalami in child-onset MS. Neurology. 2012;78:194-201.

104. Waubant E, Ponsonby AL, Pugliatti M, Hanwell H, Mowry EM, Hintzen RQ. Environmental and genetic factors in pediatric inflammatory demyelinating diseases. Neurology. 2016;87:S20-7.

105. Mikaeloff Y, Caridade G, Tardieu M, Suissa S, group Ks. Parental smoking at home and the risk of childhood-onset multiple sclerosis in children. Brain. 2007;130:2589-95.

106. Banwell B, Bar-Or A, Arnold DL, et al. Clinical, environmental, and genetic determinants of multiple sclerosis in children with acute demyelination: a prospective national cohort study. Lancet Neurol. 2011;10:436-45.

107. Waubant E, Mowry EM, Krupp L, et al. Common viruses associated with lower pediatric multiple sclerosis risk. Neurology. 2011;76:1989-95.

108. Langer-Gould A, Brara SM, Beaber BE, Koebnick C. Childhood obesity and risk of pediatric multiple sclerosis and clinically isolated syndrome. Neurology. 2013;80:548-52

109. Gianfrancesco MA, Acuna B, Shen L, et al. Obesity during childhood and adolescence increases susceptibility to multiple sclerosis after accounting for established genetic and environmental risk factors. Obes Res Clin Pract. 2014:8:e435-47.

110. Hedstrom AK, Lima Bomfim I, Hillert J, Olsson T, Alfredsson L. Obesity interacts with infectious mononucleosis in risk of multiple sclerosis. Eur J Neurol. 2015;22:578-e38.

111. Hedstrom AK, Lima Bomfim I, Barcellos L, et al. Interaction between adolescent obesity and HLA risk genes in the etiology of multiple sclerosis. Neurology. 2014:82:865-72.

112. McDonald J, Graves J, Waldman A, et al. A case-control study of dietary salt intake in pediatric-onset multiple sclerosis. Mult Scler Relat Disord. 2016;6: 87-92.

113. Bhargava P, Steele SU, Waubant E, et al. Multiple sclerosis patients have a diminished serologic response to vitamin D supplementation compared to healthy controls. Mult Scler. 2016;22:753-60.

114. Disanto G, Magalhaes S, Handel AE, et al. HLA-DRB1 confers increased risk of pediatric-onset MS in children with acquired demyelination. Neurology. 2011;76:781-6.

115. van Pelt ED, Mescheriakova JY, Makhani N, et al. Risk genes associated with pediatric-onset MS but not with monophasic acquired CNS demyelination. Neurology. 2013;81:1996-2001.

116. Waubant E, Mowry EM, Krupp L, et al. Antibody response to common viruses and human leukocyte antigen-DRB1 in pediatric multiple sclerosis. Mult Scler. 2013;19:891-5.

117. Graves JS, Barcellos LF, Shao X, et al. Genetic predictors of relapse rate in pediatric MS. Mult Scler. 2016;22:1528-35.

118. Quintana FJ, Patel B, Yeste A, et al. Epitope spreading as an early pathogenic event in pediatric multiple sclerosis. Neurology. 2014;83:2219-26.

119. Vargas-Lowy D, Kivisakk P, Gandhi R, et al. Increased Th17 response to myelin peptides in pediatric MS. Clin Immunol Rev (Orlando, Fla). 2013;146:176-84.

120. Bar-Or A, Hintzen RQ, Dale RC, Rostasy K, Bruck W, Chitnis T. Immunopathophysiology of pediatric CNS inflammatory demyelinating diseases. Neurology. 2016;87:S12-9.

121. Chitnis T, Tardieu M, Amato MP, et al. International Pediatric MS Study Group Clinical Trials Summit: meeting report. Neurology. 2013;80:1161-8.

122. Ghezzi A. Randomized clinical trial in pediatric multiple sclerosis: are they really necessary? Mult. Scler. J. 2016. doi:10.1177/1352458516684025.

123. Chitnis T, Tenembaum S, Banwell B, et al. Consensus statement: evaluation of new and existing therapeutics for pediatric multiple sclerosis. Mult Scler. 2012;18:116-27.

124. Ghezzi A, Banwell B, Boyko A, et al. The management of multiple sclerosis in children: a European view. Mult Scler. 2010;16:1258-67. 
125. Ghezzi A, Amato MP, Makhani N, Shreiner T, Gartner J, Tenembaum S. Pediatric multiple sclerosis: Conventional first-line treatment and general management. Neurology. 2016;87:S97-S102.

126. Krupp LB, Pohl D, Ghezzi A, et al. Subcutaneous interferon beta-1a in pediatric patients with multiple sclerosis: Regional differences in clinical features, disease management, and treatment outcomes in an international retrospective study. J Neurol Sci. 2016;363:33-8.

127. Ghezzi A, Pozzilli C, Grimaldi LM, et al. Natalizumab in pediatric multiple sclerosis: results of a cohort of 55 cases. Mult Scler. 2013;19:1106-12.

128. Kornek B, Aboul-Enein F, Rostasy K, et al. Natalizumab therapy for highly active pediatric multiple sclerosis. JAMA Neurol. 2013;70:469-75.

129. Chitnis T, Ghezzi A, Bajer-Kornek B, Boyko A, Giovannoni G, Pohl D. Pediatric multiple sclerosis: Escalation and emerging treatments. Neurology. 2016;87:S103-9.

130. Ghezzi A, Moiola L, Pozzilli C, et al. Natalizumab in the pediatric MS population: results of the Italian registry. BMC Neurol. 2015;15:174.

131. Fragoso YD, Alves-Leon SV, Barreira AA, et al. Fingolimod prescribed for the treatment of multiple sclerosis in patients younger than age 18 years. Pediatr Neurol. 2015;53:166-8.

132. Makhani N, Schreiner T. Oral dimethyl fumarate in children with multiple sclerosis: a dual-center study. Pediatr Neurol. 2016;57:101-4.

133. Muraro PA, Pasquini M, Atkins HL, et al. Long-term Outcomes After Autologous Hematopoietic Stem Cell Transplantation for Multiple Sclerosis. JAMA Neurol. 2017. doi:10.1001/jamaneurol.2016.5867. [Epub ahead of print].

134. Krupp LB, Rintell D, Charvet LE, Milazzo M, Wassmer E. Pediatric multiple sclerosis: perspectives from adolescents and their families. Neurology. 2016;87:S4-7.

135. Scalfari A, Lederer C, Daumer M, Nicholas R, Ebers GC, Muraro PA. The relationship of age with the clinical phenotype in multiple sclerosis. Mult Scler. 2016;22:1750-8.

136. Pfeifenbring S, Bunyan RF, Metz I, et al. Extensive acute axonal damage in pediatric multiple sclerosis lesions. Ann Neurol. 2015;77:655-67.

\section{Submit your next manuscript to BioMed Central and we will help you at every step:}

- We accept pre-submission inquiries

- Our selector tool helps you to find the most relevant journal

- We provide round the clock customer support

- Convenient online submission

- Thorough peer review

- Inclusion in PubMed and all major indexing services

- Maximum visibility for your research

Submit your manuscript at www.biomedcentral.com/submit 